\title{
Dimensiunea alterității în romanele Fundamentalist fără voie (2007) și Exit West (2017) de Mohsin Hamid
}

\author{
Lector univ. dr. Oana-Celia GHEORGHIU \\ Universitatea „Dunărea de Jos” din Galați
}

\begin{abstract}
The present paper proposes an alternative to the well-established notion that postcolonial literature is still a marginal literary category in the twenty-first century, trying to demonstrate that, in fact, postcolonial voices have long occupied a forefront position in the reception of the critics and general public alike, gradually turning their books into both successful marketable products and ideological weapons. Reasons may vary from the readers' mere interest in becoming acquainted with the culture of a perpetual other that has moved closer in space after the fall of the colonial empires to guilt for the past treatment of these territories and of their peoples. From the radical approaches to postcolonialism in the 1950s-1960s, which have now become classical theoretical texts, to the cultural and historical affirmation in the 1980s and reaffirmation of identity, in the context of rising Islamophobia after 9/11, writers labelled as postcolonial now push the boundaries, heading straight to the centre of the Western Canon. Asserting their identity, either in 'je suis l'autre' fashion or by highlighting their hybridity, the literary voices of the East are no longer just an exotic niche of English literature. A good case in point is Mohsin Hamid, Pakistani-British author whose novels, nominated for important Western literary prizes, provide a fresh perspective of what means to be the other in the eyes of the West.
\end{abstract}

Keywords: postcolonialism, otherness, Muslim identity, East-West, contemporary fiction

\section{Postcolonialism, alteritate și anularea marginalității}

Categorie cu debut și parcurs inițial marginal, evoluând dinspre granițele îndepărtate ale fostelor imperii coloniale din secolul al XIX-lea și din prima jumătate a secolului al XX-lea spre Europa și Statele Unite, literatura postcolonialistă de expresie engleză începe să câștige notorietate în anii 19701980, mai întâi în mediul academic, odată cu dezvoltarea Studiilor culturale și a Materialismului cultural, inspirate de stânga radicală și preocupate de analizarea relațiilor de putere la toate nivelurile culturale. Teoria postcolonialistă, aplicată nu doar literaturii, ci și altor domenii ale vieții sociale, 
începe să fie definită odată cu publicarea unor texte devenite, între timp, canonice. Psihologul, filosoful și revoluționarul radical martinican Frantz Fanon, cu ale sale scrieri Peau noire, masques blancs (Piele neagră, măști albe) (1952) și, mai ales, Les Damnés de la terre (Blestemații pământului) (1961), este, în general, creditat ca fiind printre primii autori de referinţă ai postcolonialismului teoretic. Printre alte lucrări fără de care studiile postcolonialiste ar fi rămas, poate, în penumbră, trebuie neapărat amintite: Orientalism (1978) de autorul american de origine palestiniană Edward Said, cu o analiză a relațiilor dintre Occident și „celălalt", reprezentat de Orient, eseul Can the Subaltern Speak? (Poate subalternul să vorbească?), de teoreticiana indiană Gayatri Chakravorty Spivak, care implică o perspectivă combinată a studiilor postcolonialiste și a celor de gen și introduce termenul de othering (aproximativ, alterizare) pentru a discuta reducerea la tăcere a celuilalt, a subalternului, în condițiile eurocentrismului. Deosebit de relevante spre sfârșitul secolului trecut, precum și în paradigma multiculturalistă a secolului XXI sunt lucrările Nation and Narration (Națiune și narațiune) (1990) și The Location of Culture (Localizarea culturii) (1994) de Homi K. Bhabha, acesta din urmă fiind "responsabil" de aducerea/ menținerea în contemporaneitate a colonialismului, în loc de abandonarea acestuia în trecut, ca influență constantă asupra înțelegerii relațiilor interculturale și asupra multiculturalismului, precum și de introducerea unor noi termeni și concepte, cele mai cunoscute fiind hibridizarea, mimetismul, și ambivalența.

În ceea ce privește postcolonialismul literar, treptat, odată cu publicarea unor romane de succes, care au trecut proba timpului, cum ar fi cele ale autoarei sud-africane Nadine Gordimer, ale nigerianului Chinua Achebe sau ale autorului indo-caraibian V.S. Naipaul, laureat al Premiului Nobel pentru Literatură în 2001, literatura circumscrisă acestei categorii începe să-și facă loc tot mai pregnant printre domeniile de interes ale criticilor literari, pe de o parte, dar și printre preferințele publicului cititor. Occidentul începe să devină din ce în ce mai interesat de vocea celuilalt, poate din curiozitate intelectuală, poate pentru a-l înțelege și integra pe acesta din urmă, având în vedere aproprierea socio-geografică produsă de fenomenul migrației înspre centru (adică înspre teritoriile actuale ale fostelor puteri coloniale) sau poate și ca rezultat al unei corectitudini politice din ce în ce mai accentuate, al unui complex de vinovăție moștenită și al nevoii de a compensa pentru neajunsurile suferite de către reprezentanții acestor culturi în perioada imperialist-colonială. Un moment de referință în literatura britanică postmodernă - fie aceasta cu accente postcoloniale sau nu - îl reprezintă apariția, în 1981, a romanului Midnight's Children (Copiii de la miezul nopții) de Salman Rushdie, celebrul autor de origine 
indiană. Romanul, o alegorie magic-realistă a renașterii Indiei odată cu obținerea independenței de sub autoritatea coroanei britanice, probabil una dintre cele mai complete și reușite ilustrări ale conceptului de „istoriografie metaficțională” (Hutcheon 1989), a câștigat prestigiosul premiu Man Booker în anul 1981 și a primit distincția Best of the Booker în 1993 și 2008, în ultimul caz, intrând în etapa finală, pe așa-numita listă scurtă, alături de alte câteva importante romane ale postcolonialismului: The Conservationist (Ecologistul) de Nadine Gordimer, Disgrace (Dezonoare) de J. M. Coetzee și The Siege of Krishnapur (Asediul de la Krishnapur) de J G Farrell. Intr-o lume în care ficțiunea (calitativă) nu mai poate fi izolată în turnul de fildeș al criticii literare, ea transformându-se într-un bun de consum cu impact financiar, prezența a nu mai puțin de patru romane cu accente postcolonialiste într-o listă totală care cuprinde șase titluri indică în mod incontestabil prevalența din ultimii ani a acestora pe piața literară britanică și, prin intermediul traducerilor, și pe aceea internațională.

Un alt argument demn de luat în considerare în alternativa propusă la ideea că, în secolul XXI, literatura postcolonialistă încă mai este o categorie marginală a literaturii este și faptul că, în contextul islamofobiei generate în lumea occidentală de evenimentele de la 11 septembrie 2001, numeroși autori răsăriteni, rezidenți sau cetățeni ai fostelor imperii coloniale sau ai Statelor Unite, își afirmă identitatea de tip „eu sunt Celălalt” sau își subliniază cu insistență hibriditatea. Islamofobia, manifestată la toate nivelurile sociale și culturale, s-a îndreptat (și încă se îndreaptă) adeseori asupra unor oameni a căror singură „vină” este aceea că împărtășesc origini etnice și/sau opțiuni religioase cu teroriștii. În cuvintele romancierei Kia Abdullah: "9/11 was not good publicity for Muslims. It created a palpable tension between us and the rest of the world" [11 septembrie nu a reprezentat o publicitate pozitivă pentru musulmani. A creat o tensiune palpabilă între noi și restul lumii] (2006: 53, traducerea noastră). Incercările de „detensionare” prin ficțiune venite dinspre diaspora musulmană au urmat, așadar, două direcții. Prima reunește reprezentări ale unor musulmani transformați pe nedrept în paria ai societății. Amintim aici romanele The Reluctant Fundamentalist (tradus și în limba română cu titlul Fundamentalist fără voie) de Moshin Hamid, Brick Lane de Monica Ali, Londonistani de Gautam Malkani (2006), Once in a Promised Land (A fost odată în Țara făgăduinței) (2007) de Laila Halaby, Life, Love and Assimilation (Viață, iubire și asimilare) (2006) de Kia Abdullah, sau piesa Back of the Throat (Din fundul gâtului) de Yussef El Guindi (2005). Cea de-a doua direcție, aceea a condamnărilor literare ale fundamentalismului islamic, se regăsește în creațiile unor autori 
reprezentativi, cum ar fi Yasmina Khadra (L'attentat/ Atentatul, 2005), Boualem Sansal (2084: La fin du monde, 2015, tradus în limba română cu titlul 2084. Sfârșitul lumii) și Salman Rushdie (Shalimar the Clown/ Shalimar clovnul, 2005). Lista nu este sub nicio formă exhaustivă, cele câteva titluri menționate fiind oferite doar cu titlul de exemplificare.

O asemenea „explozie” a ceea ce s-ar putea deja califica drept subgen literar nu putea trece neobservată de critica literară. Astfel, vocile literare musulmane sunt analizate în lucrări de mare întindere, cum ar fi Arab Voices in Diaspora: Critical Perspectives in Anglophone Arab Literature (Vocile arabe din diaspora: perspective critice în literatura arabă anglofonă) (2009), coordonată de către Layla Al Maleh, o lucrare cuprinzând șaptesprezece capitole, prefațate de o istorie elaborată a literaturii arabe de expresie engleză, Disorientation: Muslim Identity in Contemporary Anglophone Literature (Dezorientare: Identitatea musulmană in literatura anglofonă contemporană) (2013) de Esra Santesso, care se concentrează exclusiv asupra experienței imigrantei musulmane. Nu putem să nu amintim și colecția de interviuri British Muslim Fictions. Interviews with Contemporary Writers (Ficțiuni musulmane britanice. Interviuri cu autori contemporani) (2011), realizate de Claire Chambers, care oferă acces nemediat asupra perspectivelor autorilor musulmani asupra lumilor lor de cuvinte. Printre cele mai complexe lucrări critice despre literatura arabo-americană trebuie amintite Modern Arab American Fiction (Ficțiunea arabo-americană modernă) (2011) de Steven Salaita și Contemporary Arab-American Literature: Transnational Reconfigurations of Citizenship and Belonging (Literatura arabo-americană contemporană: reconfigurări transnaționale ale cetățeniei și apartenenței) (2014) de Carol Fadda-Conrey.

\section{Vocile sonore ale alterităţii: Mohsin Hamid}

Una dintre vocile alterității care au depășit deja „mărginirea” arbitrar trasată de clasificarea ca autor postcolonialist, îndreptându-se vertiginos, potrivit criticii de specialitate, dar și preferințelor marelui public, înspre apartenența la Weltliteratur, așa cum este înțeles termenul în secolul XXI, precum și înspre centrul canonului occidental, este autorul pakistanez-britanic Mohsin Hamid. Născut în Lahore, Pakistan în 1971, într-o familie de intelectuali, Hamid se mută la o vârstă foarte fragedă în Statele Unite, datorită unei burse doctorale la Stanford obținute de către tatăl său. Așa cum va mărturisi în repetate rânduri în interviuri, precum și în colecția de eseuri Discontent and Its Civilisations (Neajunsul și civilizațiile sale), impactul schimbării de decor și, mai ales, de fundal lingvistic, își va lăsa pentru totdeauna amprenta asupra 
personalității sale din anii maturității. Aculturalizarea/ americanizarea se produce, însă, rapid, astfel încât, la revenirea în Pakistanul natal, la vârsta de nouă ani, Hamid trece printr-o altă experiență a emigrantului, văzându-se silit să învețe din nou limba urdu, pe care o uitase complet: "I'd been so fluent in Urdu, and such a talker, that my parents never realized just how completely I'd forgotten the language until we arrived back in Pakistan. I was thrown into a strange new (old) world of extended families, aunts and uncles, two dozen cousins, cricket, oddtasting bread, still-odder-tasting-milk, only one television channel ... and an almost complete absence of familiar consumer brands" [Fusesem atât de fluent în urdu și așa de vorbăreț că părinții mei nu și-au dat seama cât de complet uitasem limba până când nu am ajuns înapoi în Pakistan. Am fost aruncat într-o nouă (veche) lume stranie de familii imense, unchi și mătuși, două duzini de veri, crichet, pâine cu gust ciudat, lapte cu gust încă și mai ciudat, un singur canal de televiziune... și absența aproape totală a mărcilor familiare.] (2014: 7, traducerea noastră). După această re-aculturalizare urmează și o a treia, odată cu plecarea la studii în Statele Unite, la Universitatea Princeton, ca să studieze literatură engleză și scriere creativă cu celebrele autoare americane Joyce Carol Oates și Toni Morrison, o a patra, în 2001, când se mută la Londra și, cel puțin deocamdată, o a cincea, la revenirea în Pakistan în 2009. Istoria contemporană plină de tumult a ultimilor ani ai secolului XX și a primelor decenii din noul mileniu pare a-l urmări oriunde merge: "I have lived in Pakistan during its recent and most intense period of terrorist activity and drone strikes, in London during the years on either side of the 2005 public transport bombings, and in New York in the era that came to an end with the attacks on the World Trade Center of 2001." [Am trăit în Pakistan în timpul recentei și celei mai intense perioade de activitate teroristă și atacuri cu drone, în Londra în anii dinainte și de după atentatul cu bombe din mijloacele de transport în comun, din 2005, și în New York în era care s-a sfârșit odată cu atentatul din 2001 de la World Trade Center] (2014: xv, traducerea noastră). În aceste condiții, nu este deloc surprinzător faptul că, dincolo de dimensiunea identitară evidentă care transpare în toate cele patru romane publicate până în prezent, Mohsin Hamid se distinge ca un scriitor angajat, un scriitor pentru care evenimentele politice nu rămân în afara unui virtual turn de fildeș al literaturii, ci se întrepătrund cu o ficțiune puternic marcată autobiografic, hibridă datorită formelor occidentale ale scriiturii și conținutului cu accente orientale, străbătut uneori, la nivel foarte conștient, de reacții cel puțin critice la adresa vestului. 


\section{Fundamentalist fără voie - De la hibridizare la islamofobie după 11 septembrie 2001}

Romanul experienței imigrantului, Exit West, pe care Hamid declară că era de așteptat să-1 scrie - „Well, I have been migrating my whole life, so, in a way, I suppose I was always going to write at some point a novel about migration" [Ei bine, am migrat toată viața, așa că, într-un fel, cred că a fost evident dintotdeauna că am să scriu la un moment dat un roman despre migrație] (interviu PBS 2018, traducerea noastră) - se lasă, cel puțin teoretic, așteptat până în 2017, apariția sa coincizând cu cutremurul social-politic care zguduie Europa odată cu sosirea, începând cu anul 2015, a valurilor imense de refugiați din Siria și nu numai. Teoretic, pentru că, de fapt, și romanul care i-a adus consacrarea pe plan internațional, The Reluctant Fundamentalist (Fundamentalist fără voie) (2007), este, în esență, tot unul al migrației, al experienței dureroase a dezrădăcinării, și nu din „solul” de origine, ci, mai grav, din „solul” în care imigrantul, devenit brusc, printr-un joc dramatic al istoriei, un „celălalt” de temut, se crezuse pe deplin integrat. Experiența alterității sau, mai bine spus, a acelui othering, este mai pronunțată în The Reluctant Fundamentalist, roman circumscris - și nu în mod eronat - subgenului literar deja consacrat sub denumirea de 9/11 fiction. Din punct de vedere tematic, ficțiunea post-11 septembrie poate fi împărțită în mai multe categorii, trauma vestului jucând un rol principal în majoritatea textelor literare, urmată îndeaproape de elemente istorico-politice, împrumutate din discursurile conducătorilor lumii și din presă, în manieră neorealistă. O categorie aparte, în care se înscrie romanul lui Hamid, ca și celelalte ficțiuni menționate mai sus, cuprinde, însă, reprezentări ale dramei musulmanului rezident în Statele Unite după 11 septembrie 2001, supus supravegherii permanente din partea oficialităților și, de multe ori, oprobriului unei societăți care are tendința de a confunda originile răsăritene cu terorismul.

Construit sub forma unui monolog dramatic inspirat în mod evident de Căderea lui Camus, romanul The Reluctant Fundamentalist este povestea extrem de subiectivă și necreditabilă pe care Changez, personajul principal, o narează unui interlocutor american întâlnit într-un bar din Lahore. Cuvântul interlocutor nu este tocmai cel potrivit, întrucât americanului nu i se dă nici măcar o dată cuvântul pe tot parcursul cărții - acesta este complet redus la tăcere, un detaliu care subliniază filonul postcolonialist al cărții, dorința de ripostă literară a unui celuilalt care s-a săturat să tacă. Așa cum precizam într-o analiză extinsă a romanului, „The American interlocutor's silence could be synecdochally interpreted as a silencing of America, a way of asserting that America 
should not have a say in the South Asian territories" [tăcerea interlocutorului american poate fi sinecdotic interpretată drept o reducere la tăcere a Americii, o modalitate de a afirma că America nu ar trebui să aibă un cuvânt de spus în teritoriile Asiei de Sud] (Gheorghiu 2018: 227). Întrebat dacă această reducere la tăcere a fost intenționată, Hamid a afirmat, într-un interviu acordat ziarului american The New York Times, că, de obicei, lucrurile stau exact pe dos, musulmanii fiind auziți în presa americană numai atunci când vorbesc în videoclipuri de slabă calitate, filmate în peșteri - aluzie la numeroasele înregistrări cu declarații ale lui Osama bin Laden, distribuite de media occidentală până la capturarea și uciderea acestuia în 2011 (Solomon 2007).

Changez este, într-o oarecare măsură, dublul ficțional al lui Hamid. Student strălucit la Princeton, bursier al Statelor Unite, el obține, imediat după finalizarea studiilor, o slujbă excelentă într-o importantă corporație (Underwood Samson, deci U.S.) și își găsește o iubită americancă, Erica, pe care Peter Morey o vede ca pe o alegorie pentru America (2011: 140). Changez pare a se îndrepta cu pași siguri spre îndeplinirea visului american. Personajul nu are nimic de-a face cu imaginea stereotipică a islamistului bigot și fanatizat, dimpotrivă, întreaga lui experiență americană pare a conduce spre o hibridizare reușită, spre integrarea în creuzetul etnic și cultural al Statelor Unite. Numai că topitoria aceasta de uniformizat identități aproape că se sfărâmă odată cu prăbușirea turnurilor gemene în urma atentatului din 11 septembrie 2001. Îngenuncheată pe propriul teritoriu, lovită crunt prin cele 3000 de pierderi de vieți omenești, dar și simbolic, prin nimicirea uneia dintre imaginile iconice ale puterii sale, America declară deschis războiul împotriva terorii, pe care îl va duce în Afghanistan (lângă Pakistanul lui Hamid) și Irak vreme de aproape un deceniu. Totodată, oficialitățile, mass-media și societatea civilă americană încep un adevărat asalt îndreptat împotriva musulmanilor din Statele Unite - percheziții și rețineri arbitrare pe aeroporturi, violențe fizice și verbale, persecuții la locul de muncă etc. Hamid surprinde cu acuratețe demnă de un realism pe care romanele lui nu îl au, de fapt, momentul 11 septembrie, urmat de marginalizarea treptată, dar completă, a lui Changez, care se vede transformându-se dintr-un produs al societății americane corporatiste într-un adevărat dușman al poporului. Odată cu aversiunea americanilor de rând și cu valul de persecuții îndreptate de către autoritățile statului împotriva musulmanilor, Changez începe să realizeze că statutul lui nu este decât acela al unui mercenar aflat în serviciul unei puteri care luptă împotriva alor săi: „I was a modern-day janissary, a servant of the American empire at a time when it was invading a country with a kinship to mine and was perhaps colluding to ensure that my own 
country faced the threat of war" [Eram un ienicer al zilelor noastre, un servitor al imperiului american într-o perioadă în care acesta invada o țară înrudită cu a mea și complota, probabil, ca să se asigure că propria mea țară se confrunta cu amenințarea războiului] (Hamid 2007: 173, traducerea noastră). Reîntoarcerea personajului în Pakistanul natal reprezintă un moment de cotitură în discursul romanesc, care devine acum vădit antiamerican, criticând deschis intervenția americană în Orient și pretențiile de superioritate ale „jandarmului lumii": "You retreated into myths of your own difference, assumptions of your own superiority. And you acted out these beliefs on the stage of the world, so that the entire planet was rocked by the repercussions of your tantrums" [V-ați retras în miturile propriei diferențe, în asumarea propriei superiorități. Și v-ați pus în practică aceste credințe pe scena mondială, așa că întreaga planetă a fost zgâlțâită de repercusiunile istericalelor voastre] (199, traducerea noastră).

Așadar, se poate afirma că ficțiunea post-11 septembrie semnată de Mohsin Hamid, care este, în paranteză fie spus, și unul dintre cele câteva mari succese internaționale ale subgenului, alături de romane ca Falling Man (Omul căzător, Polirom 2015) de Don De Lillo, Extremely Loud and Incredibly Close (Extrem de tare și incredibil de aproape, Humanitas 2007) de Jonathan Safran Foer sau Saturday (Sâmbătă, Polirom 2015) de Ian McEwan, oferă perspectiva Celuilalt asupra evenimentelor care au marcat începutul acestui mileniu. The Reluctant Fundamentalist (Fundamentalist fără voie, Paralela 45, 2009) afișează o critică de factură postcolonialistă a unui Occident puternic marcat de orientalism, în accepțiunea postcolonialistă și poststructuralistă a lui Edward Said, un Occident care nu își poate imagina orientalul decât ca pe o amenințare, refuzându-i acestuia dreptul la hibridizare și integrare pe baza unor stereotipuri construite generalizând trăsături definitorii ale unor elemente marginale și izolate ale lumii și culturii orientale, teroriștii islamiști.

\section{Exit West - Portaluri spre alteritate}

Un demers oarecum similar în intenții, deși cum nu se poate mai diferit în aparență, este și cel mai recent roman al lui Mohsin Hamid, Exit West (2017), nominalizat și acesta, ca și The Reluctant Fundamentalist, pentru Man Booker Prize. Fără a sugera că i-aș contesta în vreun fel valoarea literară, pe care o are din plin, mărturisesc că, în condițiile deschiderii Uniunii Europene către toleranță, acceptare și valori ale multiculturalismului, m-aș fi așteptat ca Exit

West chiar să fie titlul anului trecut distins cu prestigiosul premiu, datorită 
firului său narativ evocator pentru soarta sutelor de mii de refugiați ajunși, unii dintre ei în circumstanțe tragice, în Europa.

Așa cum ne-a obișnuit deja, istoria mare și semnificativă este doar un fundal pe care Hamid construiește istorii personale, mărunte a unor personaje lipsite de anvergură eroică, ba mai mult, lipsite uneori și de minimele atribute ale identității - nume, origini etc. În cazul romanului Exit West, numai cele două personaje principale primesc nume, nume de origine arabă, Saeed și Nadia, refuzându-li-se însă o localizare precisă în spațiu și timp, pentru a sugera universalitatea narațiunii. Orașul lor nenumit, dar aflat în mod evident într-o țară musulmană, este încă neafectat foarte grav de războiul civil între două facțiuni religioase. Damascul sirian și Sanaa (Yemen), chiar și Mosul (Irak), par a fi trimiteri evidente, cu toate că autorul insistă în interviurile de promovare a cărții că locul de desfășurare a acțiunii inițiale a romanului poate fi orice oraș oriental, inclusiv unul din Pakistan, într-un viitor mai mult sau mai puțin îndepărtat. Povestea de dragoste dintre cele două personaje evoluează fără dramatism, în paralel cu precipitarea evenimentelor politice, într-un crescendo excelent dozat, care transformă presupusul roman de dragoste într-unul de război. Maestru incontestabil al „penelului” literar, Hamid zugrăvește cu un lirism aparte imagini violente, de inspirație naturalistă, pe care le alternează cu relatări scurte, reportericești, construind un univers bolnav, un adevărat „paradis în destrămare” pe care cele două personaje principale se văd silite să-1 lase în urmă pentru a scăpa cu viață, dar și pentru a prilejui lungi meditații asupra condiției imigrantului, redate - cum altfel? - prin tehnica discursului indirect liber.

Fuga de realism literar a lui Hamid se manifestă în Exit West prin recurs la realismul magic - ieșirea din zona de conflict se poate face numai prin uși magice, patrulatere negre apărute din senin în locul ușilor obișnuite, prin care refugiații pot trece, contracost și cu mari riscuri, de partea cealaltă, spre vestul văzut invariabil ca spațiu mitic al salvării. Trimiterea evidentă la Cronicile din Narnia, ca și întregul element de magie, de altfel, se oprește, însă, imediat după trecerea prin aceste portaluri. Pentru că destinațiile, de această dată numite - în ordine cronologică, insula grecească Mykonos, Londra și orășelul californian Marin, aflat pe coasta Pacificului, în apropriere de San Francisco -, reprezintă tot atâtea puncte pe drumul transformării celor două personaje în reprezentări ale unei alterități orientale indezirabile. Viața dură din tabăra de refugiați de pe insula grecească amintește pregnant de imaginile dramatice ale existenței duse de refugiații sirieni, surprinse de televiziunile din toată lumea în vara anului 2015. Dar, cu tot fotorealismul descrierilor sale, Hamid nu face altceva decât să 
anticipeze, să construiască gradual alteritatea extremă și violentă pe care cele două personaje o vor experimenta la sosirea în Londra. Episodul londonez al fugii celor doi de realitatea războiului reprezintă o critică nemascată la adresa Occidentului, urmare a recrudescenței ideologiilor de extremă dreaptă, ca răspuns la impunerea Uniunii Europene asupra statelor membre de acceptare a unui număr de azilanți și refugiați din zonele orientale de conflict. Fugind de un război civil care le-a distrus orașul natal și le-a răpit persoane dragi, victime colaterale ale unui conflict religios absurd, Saeed și Nadia ajung într-o Londra distopică, în mijlocul unui război al celor două lumi, cea occidentală percepând prezența refugiaților ca pe o invazie, iar cea orientală agățându-se cu disperare de o pace deja inexistentă.

$\mathrm{Cu}$ toată critica la adresa extremismului de dreapta al europenilor, Hamid menține, totuși, un ton echilibrat în privința crizei mondiale a refugiaților: "I can understand it, she said. "Imagine if you lived here. And millions of people from all over the world suddenly arrived." "Millions arrived in our country," Saeed replied. "When there were wars nearby." "That was different. Our country was poor. We didn't feel we had as much to lose." [„Pot să înțeleg," spuse ea. „Imaginează-ți că ai fi trăit aici. Și milioane de oameni din toată lumea ar fi venit deodată." "Și în țara noastră au venit milioane" îi răspunse Saeed. „Când erau războaie în regiune.” „Asta-i altceva. Țara noastră era săracă. Nu am simțit că avem atât de mult de pierdut."] (Hamid 2017: 162, traducerea noastră).

Dacă alteritatea lui Changez din romanul The Reluctant Fundamentalist se produce treptat, pornind de la o confortabilă integrare și asimilare a culturiigazdă, așa cum am arătat mai sus, pe fondul accentuării neîncrederii în musulmani sau, în unele cazuri, chiar a urii față de aceștia după atentatele de la 11 septembrie 2001, alteritatea lui Saeed și a Nadiei rămâne totală pe toată durata refugiului lor în lumea considerată pașnică din spatele ușilor magice. Exit West înfățișează o lume a unor realități aproape paralele cu realitățile Occidentului, o lume care, în ciuda apropierii spațiale, geografice, rămâne una a celorlalți, o lume în care sinele culturii-gazdă nu vrea să aibă nimic de-a face cu alteritatea, a cărei prezență o simte ca fiindu-i impusă. Exceptând scenele de război civil din Londra, nou-sosiții nu au nicio formă de comunicare cu cei deja prezenți, refugiații rămân izolați în enclave minoritare, iar integrarea și hibridizarea nu ating nici măcar orizontul așteptării, al iluziei că perechea binară sine-celălalt ar putea vreodată să se întâlnească. Dacă viziunea aceasta, mai pesimistă chiar decât aceea din romanul-reacție la islamofobia americană post-11 septembrie, se datorează detașării lui Hamid de influențele sale occidentale sau observării de la distanță, probabil subiective, a modului în care 
Europa a gestionat și încă gestionează criza refugiaților din Orient este mai puțin relevant. Ceea ce contează, însă, din punct de vedere al discursului romanesc, este faptul că „ieșirea spre vest” pare a fi din nou inaccesibilă și că, pe fundalul realităților politice, al recrudescenței extremismului de dreapta european, o voce importantă a postcolonialismului literar contemporan devine mai conștientă de diferențele dintre cele două lumi.

\section{Bibliografie}

Abdullah, Kia. 2006. Life, Love and Assimilation. Londra: Adlibbed Ltd.

Al Maleh, Layla. 2009. Arab Voices in Diaspora: Critical Perspectives in Anglophone Arab Literature. Amsterdam/ New York: Rodopi.

Bhabha, Homi K. 1990. Nation and Narration. Londra: Routledge.

Bhabha. Homi K. 2004. The Location of Culture (ed. a II-a). Londra: Routledge.

Chambers, Claire. 2011. British Muslim Fiction. Interviews with Contemporary Writers. Hampshire: Palgrave.

Fadda-Conrey, Carol. 2014. Contemporary Arab-American Literature: Transnational Reconfigurations of Citizenship and Belonging, New York University Press.

Fanon, Frantz. 1993. Peau noire, masques blancs. Paris: Editions du Seuil.

Fanon, Frantz. 2004. Les Damnés de la terre. Paris: La Découverte.

Gheorghiu, Oana-Celia. 2018. British and American Representations of 9/11 Literature, Politics and the Media. Cham: Palgrave Macmillan.

Hamid, Mohsin. 2007. The Reluctant Fundamentalist. Londra: Penguin Books.

Hamid, Mohsin. 2014. Discontent and Its Civilizations. Londra: Penguin Books.

Hamid, Mohsin. 2017. Exit West. Londra: Penguin Books.

Hutcheon, Linda. 1989. "Historiographic Metafiction Parody and the Intertextuality of History" in O'Donnell, P., Robert Con Davis (eds.) Intertextuality and Contemporary American Fiction. Baltimore: Johns Hopkins University Press, 3-32.

Morey, Peter. 2011. 'The Rules of the Game Have Changed: Mohsin Hamid's The Reluctant Fundamentalist and Post-9/11 Fiction`. Journal of Postcolonial Writing 47 (2). 135-146.

Said, Edward. 2003. Orientalism (ed. a III-a). Londra: Penguin Classics.

Salaita, Steven. 2011. Modern Arab American Fiction. Syracuse University Press.

Santesso, Esra. 2013. Disorientation: Muslim Identity in Contemporary Anglophone Literature. Hampshire: Palgrave Macmillan. 
Solomon, Deborah. 2007. 'The Stranger - Interview with Mohsin Hamid'. The New York Times, 15 aprilie 2007.

Spivak, Gayatri Chakravorty. 1988. Can the Subaltern Speak? In Cary Nelson si Lawrence Grossberg (ed) Marxism and the Interpretation of Culture. University of Illinois Press, 271-313. 